\title{
LETTERS
}
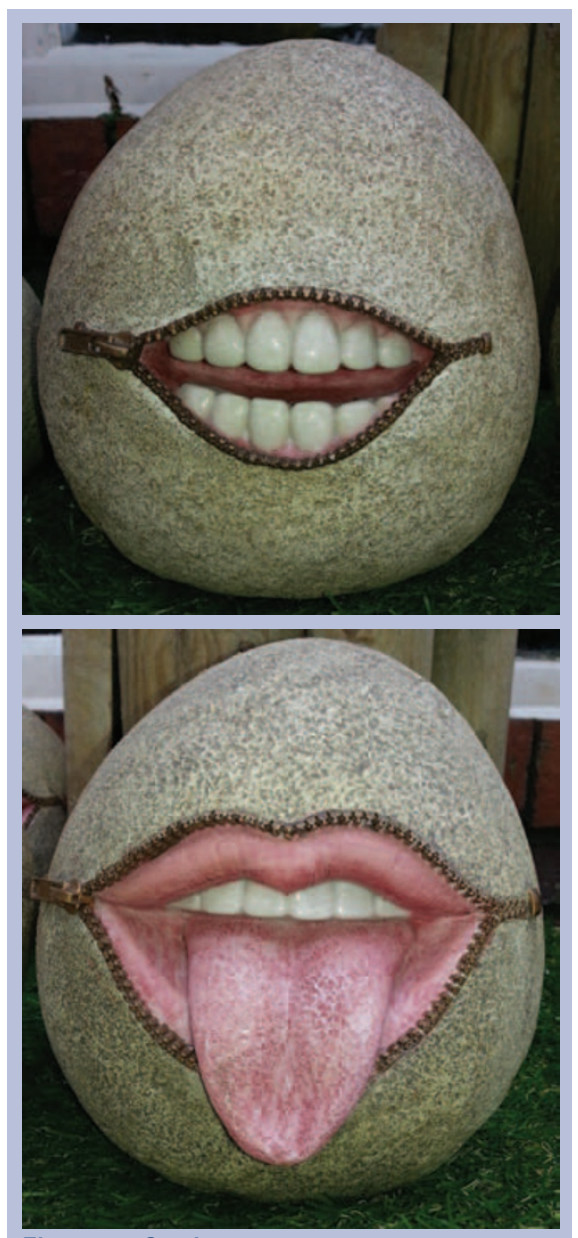

Figs 1-2 Garden centre art

It is good to see that such unzipped stones are demonstrating a good oral hygiene example.

R. M. Graham, by email DOI: 10.1038/sj.bdj.2013.441

\section{CONTRARY TO ASPIRATION}

Sir, I am writing to share some comments recently circulated by me as chair of a local professional network (LPN), the Teesside Sedation Network Group (TSNG), regarding the current procurement process for NHS sedation services in our region. LPNs are being heralded as a great opportunity to improve outcomes for patients across the country and make the best use of skilled professionals who meet many patients every day in their communities.

The TSNG is a group of interested sedation providers who have formed links between sedation performers, providers, referrers, commissioners and contract managers since 2009. I am one of the partners of the service which has delivered safe and effective evidence based conscious sedation for the last
14 years, so clearly have a personal

interest in this process.

Teesside is a unique region as it has some of the highest levels of dental disease in the country, but low levels of dental general anaesthetics (DGAs). This is largely due to the advanced sedation (Tier 2) service in the region, which has been a gatekeeper for anxious children and adults, thereby reducing direct referral to hospital for DGAs, if simple sedation (Tier 1) techniques are inadequate.

It is interesting that none of the current sedation providers or members of the TSNG are involved in the potential new sedation contract delivery in our region. I believe this is due to the following issues:

- The online application process was cumbersome and labour intensive

- The service design was influenced by fund holders and not clinicians

- The service design favoured a low cost model for Tier 1 or simple sedation, which does not support the management of the advanced dental disease we have to deal with in Teesside

- The overall service design is flawed with split sites for Tier 1 and Tier 2 sedation and this is likely to increase patient ping-pong

- The model for KPIs on any new provider is punative and does not encourage best practice

- Heavy dependence on referring dentists to make the correct decision on appropriate sedation techniques for anxious children and adults is not realistic

- Experienced dental sedationists are not prepared to compromise their professional standards for a low treatment cost envelope.

High standards of patient safety and quality of care are essential in a modern and progressive NHS service. These are fundamental aspects of well governanced NHS service delivery, and have been clearly highlighted by the recent Mid-Staffordshire report, showing that ill-conceived budget cuts and cost saving schemes can have a negative impact on both patient care and outcomes.

The reality of this NHS commissioning process for sedation appears to be contrary to the aspiration of forming the NHS Commissioning Board and estab- lishment of Local Professional Networks. This new NHS commissioning format has set out to ensure the highest standards of quality and safety are maintained across the NHS. Sadly, our recent experience in Teesside does not match the aspiration of these new proposals for LPNs.

I. Lane, Teesside

DOI: 10.1038/sj.bdj.2013.442

\section{DENTAL GUIDANCE FOR ALL}

Sir, I would like to draw your readers' attention to new guidance entitled Management of acute dental problems (www.sdcep.org.uk/?o=3158). This is intended for use by staff in any healthcare setting who may be asked to advise or manage patients with acute dental problems. This includes non-dental professionals, such as general medical practice, emergency department and pharmacy staff, as well as members of the dental team. The guidance is applicable to patients of all ages in all population groups, irrespective of the healthcare setting or whether they are attending their dentist regularly.

Recognising the diverse manner in which patients requiring unscheduled clinical care are managed, ${ }^{1-3}$ the Scottish Dental Clinical Effectiveness Programme (SDCEP) convened a guidance development group to support the delivery of safe and effective patient care by providing clinical guidance on best practice for the management of acute dental problems. This new guidance builds on the dental clinical guidance Emergency Dental Care ${ }^{4}$ published by the SDCEP in 2007.

Based on the main presenting symptoms, this guidance provides decision support flowcharts, which can be used to identify any immediate attention or advice to give to the patient and to determine the appropriate provider of subsequent care. An interactive electronic decision support tool is also available in web app format. This can be accessed on the Internet via a personal computer, tablet or smartphone at http://madp. sdcep.org.uk. A separate Quick Reference Guide that includes the decision support flowcharts only is also provided.

In 2003 the World Health Organisation suggested a range of oral health targets for 2020. ${ }^{5}$ These include an increase in the number of healthcare providers who 
are competent to recognise and manage a range of acute dental problems (such as infectious diseases, oral mucosal diseases and salivary gland disorders). The proposed targets also promote the early detection and appropriate referral pathway for a variety of oral conditions, including dental trauma and oro-pharyngeal cancer.

\section{A. Yeung, Bothwell}

1. Anderson R, Thomas D W. Out-of-hours dental services: a survey of current provision in the United Kingdom. Br Dent J 2000; 188: 269-274.

2. Anderson R, Thomas D W, Phillips C J. The effectiveness of out-of-hours dental services: I. pain relief and oral health outcome. Br Dent J 2005. 198: 91-97

3. Ball G E. Out-of-hours emergency dental services in Scotland - a national model. Br Dent J 2008; 205: 485-487.

4. Scottish Dental Clinical Effectiveness Programme Emergency dental care: dental clinical guidance. Dundee: Scottish Dental Clinical Effectiveness Programme, 2007

5. Hobdell M, Petersen P E, Clarkson J, Johnson N. Global goals for oral health 2020. Int Dent J 2003; 53: $285-288$.

DOI: 10.1038/sj.bdj.2013.443

\section{FRESH EXTRACTION SITES}

Sir, a patient attended with acute pain associated with a provisional bridge replacing the 22 using the 23 as an abutment. The bridge had been placed approximately two weeks previously by an emergency dentist whilst the patient was on holiday. The dentist had extracted the 22 and constructed a chairside acrylic replacement. Upon examination both 22 buccal sulcus region and the 23 were tender to percussion. Radiographic examination revealed radio-opacity of mixed density in the extraction site with considerable acute local osteitis. An apical rarefying osteitis was associated with the 23. This tooth had been root canal treated but the obturation was suboptimal in both length and condensation.

A diagnosis was made of persistent periapical periodontitis of the 23 and a possible foreign body in the extraction site. Surgical exploration and simultaneous re-root canal treatment was performed and a hard, off-white 'pellet' of acrylic removed from the site. It is most likely that this extrusion of acrylic occurred after the 22 had been removed and during the fabrication of the temporary bridge. The 23 and 22 area healed uneventfully.

The ability to provide immediate

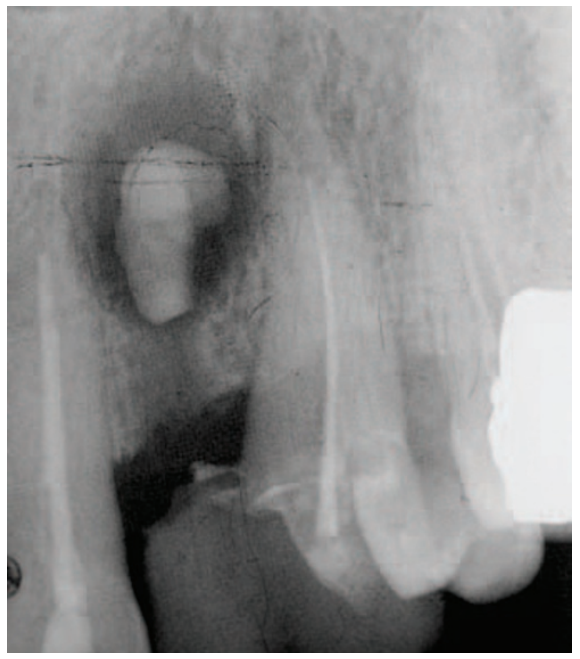

Fig. 1 Pre-operative radiograph showing radio-opaque material in the 22 site

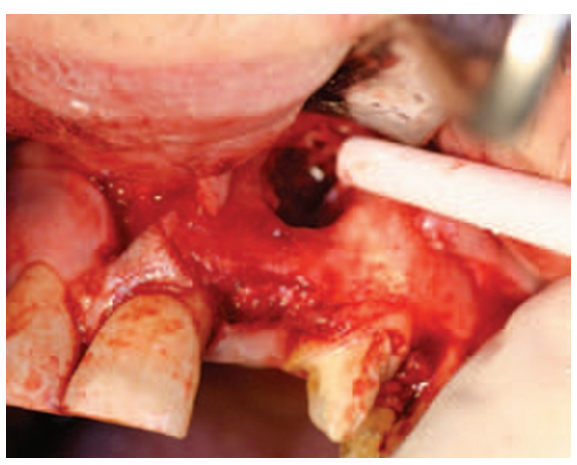

Fig. 2 Surgical exposure and removal

provisionalisation is essential in the aesthetic zone when extractions are planned. Given that post extraction and provisionalisation radiographs are rarely justified, an outcome such as this would be easy to miss. Perhaps, however, clinicians should approach fresh extraction sites with more caution, ensuring adequate clot formation or placing a resorbable haemostat prior to temporary construction. This should not be considered a novel technique for ridge preservation!

J. Darcey, by email

DOI: 10.1038/sj.bdj.2013.444

\section{GROSSLY DEFORMED BODIES}

Sir, the report about Growing bodies linked to gammy gums (BDJ 2013; 214: 221) seems to miss the elephant in the room (metaphor completely intentional).

People normally become obese by simply eating too much and moving too little. Rather than the proposal to spend money searching for a chemical excuse for their gammy gums perhaps the more obvious cause would be the sheer volume, frequency and quality of food and drink being stuffed into the mouth to maintain such a body size. Also, anyone capable of allowing their body to become so grossly deformed is not concerned with their health and so the oral hygiene is likely to be fairly dire. The causal link for this self-inflicted disease seems perfectly obvious: poor diet and oral hygiene.

A patient of mine is a shining example of how it is possible for such a person to turn their life around. He was morbidly obese and decided nothing more drastic than 'to eat a little less and to move a little more'. Within six months he had lost vast amounts of weight and his body and oral health had dramatically improved. Having made his own decision to alter his lifestyle, his weight has stayed off and his health has continued to improve.

C. Marks, by email DOI: 10.1038/sj.bdj.2013.445

\section{IDEALLY PLACED}

Sir, I read with interest the opinion piece on the delay in diagnosis in the $B D J .{ }^{1} \mathrm{I}$ commend the author in raising the profession's awareness of oral cancer screening and diagnosis. I noted with surprise that GDPs reported lack of remuneration and training to be major barriers to performing routine oral cancer screenings. Interestingly a survey in Ireland found that $89 \%$ of GDPs routinely performed intra and extraoral soft tissue examinations and 27\% providing tobacco smoking cessation advice. ${ }^{2}$

With this in mind I would like to point you all towards an article in the Journal of the Irish Dental Association, ${ }^{3}$ which goes through a simple and efficient method of performing an intraoral and extraoral examination. Those of us in primary care must remember we have a large exposure to the public and are ideally placed to screen for oral cancer or potentially malignant disorders.

G. Tait, London

1. Dave B. Why do GDPs fail to recognise oral cancer? The argument for an oral cancer checklist. Br Dent J 2013; 214: 223-225.

2. Decuseara G, MacCarthy D, Menezes G. Oral cancer: knowledge, practices and opinions of dentists in Ireland. J Ir Dent Assoc 2011; 57: 209-214.

3. MacCarthy D, Flint S R, Healy C, Stassen L F. Ora and neck examination for early detection of ora cancer - a practical guide. J Ir Dent Assoc 2011; 57: 195-199.

DOI: 10.1038/sj.bdj.2013.446 